\section{Análise química da cultura de tecidos do híbrido Clusia paralicola X Clusia weddelliana}

\section{Cláudio Augusto Gomes da Camara1"; Simone Liliane Kiszenzarff Shepherd²; Dulce Regina Garcia Joaquim ${ }^{3}$}

${ }_{1}^{1}$ Departamento de Química, Universidade Federal Rural de Pernambuco, 52171-900, Recife, PE

${ }^{2}$ Instituto de Química, Universidade Estadual de Campinas, CP 6154, 13083-970, Campinas, SP

${ }^{3}$ Departamento de Fisiologia Vegetal, Universidade Estadual de Campinas, CP 6154, 13083-970, Campinas, SP, Brasil claucamara@uol.com.br

\section{Resumo}

A cultura de calos de C. paralicola X C. weddelliana a partir de folhas jovens foi estabelecida por meio da combinação dos fitorreguladores ácido indol acético (AIA) e 6furfurilaminopurina (KIN). Monitoramento químico por CG/EM revelou que os metabólitos biossintetizados são excretados para o meio de cultura e são constituídos principalmente de ésteres metílicos, hidrocarbonetos de cadeia longa, triterpenos e compostos fenólicos. Os ácidos olean-12-en-3-oxo-28-óico, olean-3-oxo-28-óico e cítrico, metabólicos secundários isolados a partir do látex do fruto de $C$. grandiflora e da casca do fruto de C. nemorosa respectivamente, também foram detectados.

O gênero neotropical Clusia (Guttiferae) compreende cerca de 250 espécies, distribuídas desde o sudoeste da Flórida até o sudoeste brasileiro ${ }^{1}$. $\mathrm{O}$ uso de plantas deste gênero, no tratamento de hipertensão arterial é bastante comum na medicina popular da Costa Rica². Análise química das resinas tem revelado, que são basicamente constituídas de benzofenonas poliisopreniladas $^{3}$ e estudo de atividades biológicas, dessa classe de compostos, indicaram atividade antimicrobiana e anti$\mathrm{HIV}^{4}$. O fato de estas benzofenonas serem encontradas, quase que exclusivamente, nas resinas e nos frutos restringindo sua disponibilidade e uso na medicina popular, em qualquer época do ano, estimulou estudos da cultura de tecidos de espécies de Clusia visando uma fonte contínua destes metabólitos. Balansard e Pellissier constataram que os metabólitos presentes no látex de Clusia rosea inibiam a ação de fitorreguladores empregados no cultivo in vitro ${ }^{5}$. Diante destas dificuldades, bastante comum em plantas laticíferas, o nosso trabalho foi realizado com o híbrido $C$. paralicola x $C$. weddelliana, que geralmente possuem menor quantidade de látex do que os respectivos parentais.

De todas as combinações elaboradas em delineamento em blocos aleatórios entre auxinas/citocininas, no cultivo in vitro de explantes foliares de C. paralicola x $C$. weddelliana, a única que resultou em desdiferenciação, ou seja, formação de calo foi entre AIA e KIN e que os melhores resultados foram obtidos com 5,0 mg/l de AIA e 0,1 mg/l de KIN e 5,0 mg/l de AIA e 1,0 mg/l de KIN. Em geral, para este protocolo, o maior percentual de explantes oxidados foi encontrado naqueles cultivados em presença de luz e que a melhor interação entre os fitorreguladores, que parece minimizar a oxidação dos explantes, é aquela em que os intervalos das concentrações entre AIA/ KIN são respectivamente, 5,0 - 10,0 mg/l e 0,1 - 1,0 mg/l.

A análise por CG/EM dos calos e meio de cultura revelou que nestas condições de cultivo, foram produzidos principalmente ácidos graxos saturados e insaturados normais e ramificados, álcoois de cadeia longa, hidrocarbonetos de cadeia longa, compostos fenólicos como catequina e derivados do ácido benzóico e triterpenos (Tabela 1). Os ácidos palmítico e esteárico, caracterizados no meio de cultura, são os mais abundantes e estão presentes em ambos os calos com diferentes idades. Já os ramificados (metil-tetra, penta e hexadecanóico) foram produzidos apenas no calo cultivado por mais tempo (8 meses). A produção de ácido cítrico, detectado em calos com 28 dias e com 8 meses, pode estar relacionado às condições de estresse (anaeróbica e na ausência de luz) em que os explantes foram cultivados. Há relatos na literatura ${ }^{6,7}$ de acúmulo de ácido cítrico, em resposta ao estresse, em plantas pertencentes ao Metabolismo Ácido de Crassuláceas (CAM), que estão adaptadas à ambientes com escassez de água, sendo observado para algumas espécies de Clusia. Outros metabólitos caracterizados em ambos os calos de diferentes idades, foram os ácidos olean-12-en-3-oxo-28-óico e olean-3-oxo-28-óico. Neste caso, os maiores percentuais relativos destes ácidos foram obtidos na análise do calo 1 e no respectivo meio de cultura. Já que os metabólitos produzidos no calo são eliminados para o meio de cultura, é possível que o menor percentual relativo dos triterpenos observado no calo com 8 meses de idade esteja relacionado à realização das subculturas, cujo meio de cultura foi desprezado.

O cultivo de explantes na ausência de luz foi imprescindível para formação de calo. O protocolo ora estabelecido para cultura de células do híbrido Clusia paralicola X Clusia weddelliana promoveu a produção dos ácidos olean12-en-3-oxo-28-óico e olean-3-oxo-28-óico os quais estão presentes principalmente no látex dos frutos de Clusia grandiflora (Tabela 1). 
TABELA 1. Composição percentual relativa dos constituintes químicos caracterizados por CG/EM nos calos e meios de cultura

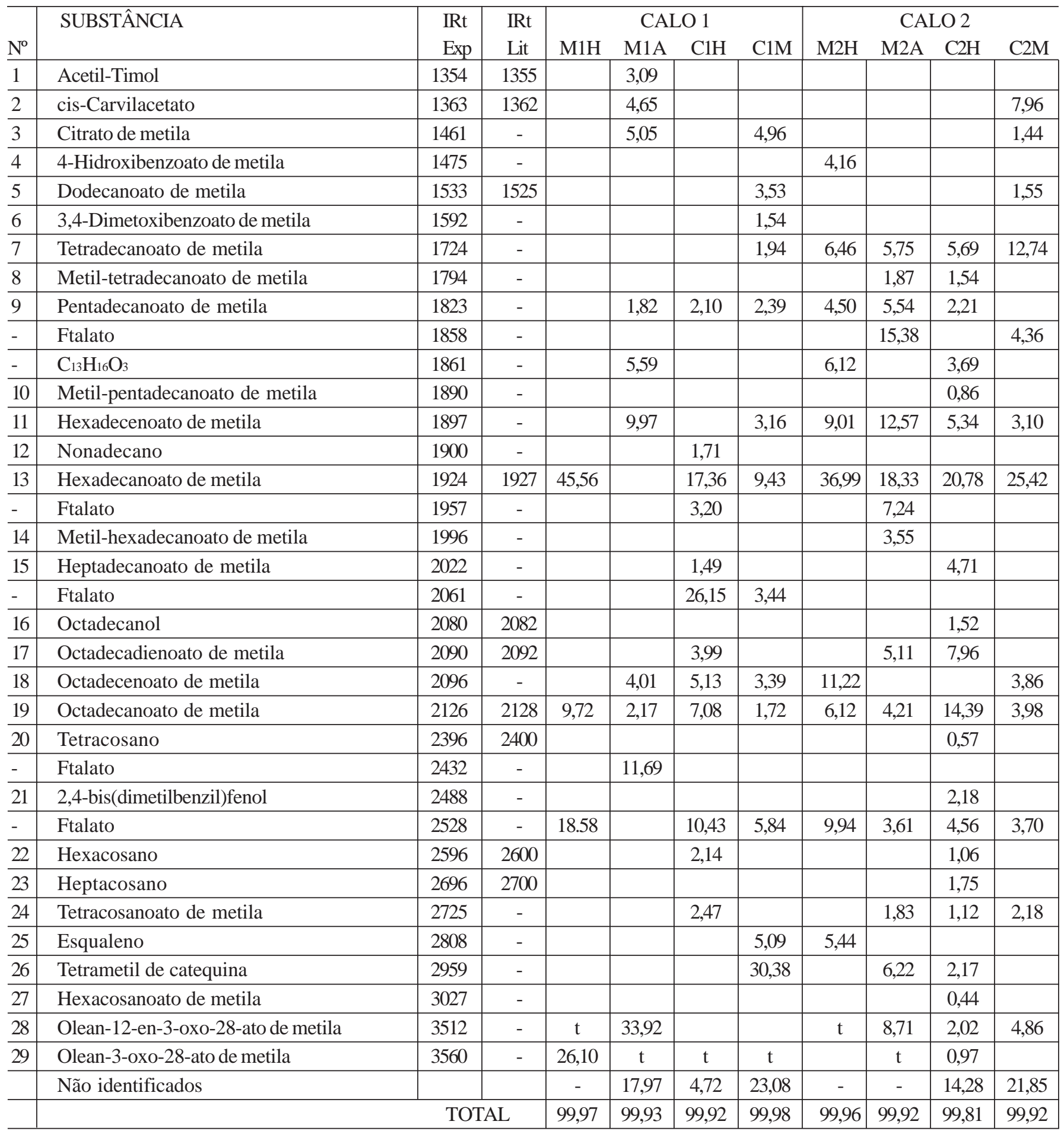

M1H e M1A = ext. hexânico e ext. acetato de etila do meio de cultura do calo $1, \mathrm{C} 1 \mathrm{H}, \mathrm{C} 2 \mathrm{H}$ e $\mathrm{C} 1 \mathrm{M}, \mathrm{C} 2 \mathrm{M}$ = ext. hexânico e metanólico do calo 1 e 2 IRt Exp. = índice de retenção obtido aplicando a equação de van den Dool e Kratz ${ }^{9}$. IRt Lit. = índice de retenção da literatura ${ }^{10}$

Um fato observado, altamente relevante do ponto de vista biotecnológico, é que as substâncias produzidas pela cultura de tecidos de $C$. paralicola x $C$. weddelliana são excretados para o meio de cultura, o que além de minimizar os custos, permite um processo contínuo de extração destes metabólitos.

Finalmente este trabalho exploratório, único deste gênero desde a tentativa de cultivo in vitro, com folhas de $C$. rosea, por Balansard e col..$^{5}$ permitiu estabelecer um protocolo para obtenção de calos a partir de explantes foliares de $C$. paralicola x C. weddelliana, cuja composição química se apresentou distinta das plantas de origem, porém com alguns triterpenos em comum. 


\section{Material e Métodos}

O híbrido foi obtido através da polinização artificial (M.C.E. Amaral e V. Bittrich) a partir de clúsias cultivadas no Instituto Agronômico de Campinas e mantidas em casa de vegetação do Departamento de Botânica da UNICAMP. Os explantes foram preparados a partir de folhas jovens de $C$. paralicola $x$ C. weddelliana, As folhas foram coletadas em julho de 1998. Os extratos hexânico, metanólico do calo e acetato de etila dos respectivos meios de cultura foram obtidos a partir de diferentes idades, com 28 dias e com 8 meses de cultivo, denominados respectivamente de calo 1 e calo 2 .

O cultivo in vitro do híbrido $C$. paralicola $x C$. eddelliana utilizou folhas apicais, em fase final de expansão a partir de pré-tratamento com fungicida benomil (solução $10 \%$ por 40 min) e esterilização superficial com hipoclorito de sódio (solução 1,5\% acrescida de uma gota de tween 20 por $20 \mathrm{~min}$ ). Os explantes não oxidados e viáveis foram colocados no meio de composição salina e orgânica de Murashige \& $\operatorname{Skoog}^{8}$ com as seguintes combinações de fitorreguladores: AIA $(0 ; 2,5 ; 5 ; 10$; $25), 2,4-\mathrm{D}(0 ; 0.1 ; 1 ; 1.5)$, BA $(0 ; 0.1 ; 1 ; 5)$ e $\operatorname{KIN}(0 ; 0.1 ; 1)$. Foram feitos várias combinações de auxina/citocinina com delineamento de blocos ao acaso. $\mathrm{O}$ cultivo foi realizado a $25 \pm 2{ }^{\circ} \mathrm{C}$ na presença e ausência de luz. Os calos obtidos com idades diferentes foram macerados a temperatura ambiente inicialmente com hexano seguido por metanol. O meio de cultura foi partionado com hexano seguido por acetato de etila. Cada extrato foi filtrado e evaporado sob pressão reduzida. O extrato metanólico e o acetato de etila foram previamente derivatizados com uma solução etérea saturada de diazometano. Os extratos foram analisados por um cromatógrafo Hewlett Packard 5890B SERIES II, acoplado a um espectrômetro de massas HP 5970, equipado com coluna capilar de sílica fundida J e W Scientific DB-5 ou HP-5 (30 m x 0.25 mm x $0.25 \mathrm{~mm}$ ). As temperaturas do injetor e detector foram respectivamente de $290^{\circ} \mathrm{C}$ e $285^{\circ} \mathrm{C}$. O gás de arraste foi Hélio e o programa de temperatura do forno foi de $40^{\circ} \mathrm{C}$ até $290^{\circ} \mathrm{C}$ à $4^{\circ} \mathrm{C} /$ min. Os espectros de massas foram obtidos à $70 \mathrm{eV}, 0,84 \mathrm{scan} /$ sec de $\mathrm{m} / \mathrm{z} 40$ a 550 e os compostos foram identificados baseados nos índices de retenção ${ }^{9} \mathrm{e}$ comparação dos espectros de massas do banco de dados (270.000 espectros) Wiley/NBS e com os da literatura ${ }^{10}$.

\section{Referências}

${ }^{1}$ Bittrich, V, Amaral MCE. Floral biology of some Clusia species from Central Amazonia. Kew Bulletin 1997; 53: 617-35

${ }^{2}$ Gonzáles, MG. \& Matamoros, OM. Efectos cardiovasculares del extrato acuoso de las hojas de Clusia conclensis (Guttiferae). Revista de Biologia Tropical 1996; 44: (1), 87-91
${ }^{3}$ Oliveira, CMA, Porto, AM, Bittrich, V, Vencato, I, Marsaioli, AJ. Floral resins of Clusia spp: chemical composition and biological function., Tetrahedron Letters 1996; 37: (36), 6427-30

${ }^{4}$ Gustafson, KR, Blunt, JW, Munro, MHG, Fuller, RW, Mckee, TC, Cardellina, JH, MacMhon, JB, Cragg, GM, Boyd, MR. The guttiferones, HIV-inhibitory benzophenones from Symphonia globulifera, Garcinia livingstonei, Garcinia ovaliforlia and Clusia rosea. Tetrahedron 1992; 48: (46), 1009310102

${ }^{5}$ Balansard, J, Pellissier, F. Le bouturage foliare et l'action inhibitrice des produits de secretion naturelle des plantes. Compt. Rend. Soc. Biol 1942; 136: 307-8

${ }^{6}$ Franco AC, Olivares E, Ball E, Luttge U, Haagkerwer A. In-situ studies of cassulacean acid metabolism in several sympatric species of tropical trees of the genus Clusia. New Phytologist 1994; 126: (2) 203-11

${ }^{7}$ Franco, AC, Ball, E, Luttge, U. Differential-effects of drougt and light levels on accumulation of citric and malic acids dring CAM in Clusia. . Plant Cell and Environment 1992; 15: (7), 821-29

${ }^{8}$ Murashige,T, Skoog, F. A revised medium for rapid growth and bio assays with tobacco tissue cultures. Physiologia Plantarum 1962; 15: (3) 473-97

${ }^{9}$ Van den Dool, H, Kratz, PD. A generalization of retention index system including linear temperature programmed gas-liquid partition chromatography. Journal of Chromatography 1963; 11: (4) 463-72

${ }^{10}$ Adams, R.P. Identification of essential oil by gas chromatography/mass spectroscopy. Allured Publishing Co, Illinois. 1995 